\title{
As condições do ensino de Filosofia no Estado do Tocantins
}

\section{Conditions of Philosophy teaching in Tocantins State}

\section{Márcio Antônio Cardoso Lima}

Professor Adjunto II do curso de Pedagogia do Câmpus Universitário de Miracema/UFT, Doutor em Educação pela Faculdade de Educação da Universidade Federal de Minas Gerais (UFMG), Belo Horizonte, MG - Brasil, e-mail: marcioacl@uft.edu.br

\section{Resumo}

Em 2004, cinco pesquisadores brasileiros desenvolveram uma pesquisa por solicitação da Unesco para o mapeamento das condições do ensino de Filosofia nas diversas regiões brasileiras, em seus diversos níveis, com ênfase especial na educação média. Neste trabalho, o Estado do Tocantins somente aparece no que diz respeito à quantificação de aulas semanais de Filosofia no ensino médio, no caso, ao menos duas aulas semanais durante um ano. Diante disso, pus-me a seguinte inquirição: Quais são as condições do ensino de Filosofia, no nivel médio, na rede pública de ensino do Estado do Tocantins? Objetivei, assim, com base nessa problemática, investigar entre 
os(as) professores(as)/trabalhadores(as), as condições do ensino de Filosofia no Estado do Tocantins na rede pública de ensino, com ênfase no ensino médio e, consequentemente, buscar subsídios para intervenção prática, num contexto de retorno obrigatório da Filosofia para o nível médio de ensino e, por fim, servir de auxílio à criação do curso de Filosofia na Universidade Federal do Tocantins.

Palavras-chave: Ensino de filosofia. Ensino médio. Formação inicial Prática pedagógica.

\section{Abstract}

In 2004, five Brazilian researchers developed a survey upon the request of Unesco in order to map out the conditions of Philosophy in various Brazilian regions, in its various levels, with special emphasis on high school education. In the said research, the state of Tocantins only appears in reference to the quantification of weekly philosophy classes in High School, that is, at a minimum of two weekly classes during the school year. Considering this, I pursued the following line of inquiry: What are the conditions of the teaching of Philosophy in the high school level within the public school system in the state of Tocantins? Taking this question into account, I set out to investigate, among the teachers, the teaching conditions of Philosophy in the public school system in the state of Tocantins, with an emphasis on the High School level and, consequently, seek data for practical intervention, in the context of the return of Philosophy as a required subject in High School education, and to that end, contribute to the creation of the Philosophy course at the Federal University of Tocantins.

Keywords: Teaching of philosophy. High school education. Initial formation Pedagogical practice. 


\section{Introdução}

Realizei duas pesquisas sobre o ensino de Filosofia (LIMA, 2002, 2005) numa instituição particular de Ensino Superior, na qual atuei por 19 anos. No primeiro trabalho foram estudadas as condições do ensino de Filosofia na região de Governador Valadares, $\mathrm{MG}$, nos anos iniciais do Ensino Superior e, em concomitância, pesquisa-ação com alunos/trabalhadores e/ ou futuros alunos/trabalhadores dos anos iniciais dos cursos de História, Pedagogia e Psicologia.

No segundo trabalho, propus-me, inicialmente, a compreensão dos limites e das dificuldades de prática com o ensino de Filosofia, tendo como eixo orientador a prática social dos envolvidos no processo ensinoaprendizagem e, por fim, a busca de alguns princípios para o trabalho com a Filosofia pela disciplina Prática de Ensino de Filosofia, em colaboração para o seu trato em sala de aula quando se lutava pelo seu retorno ao Ensino Médio.

Após a realização desse último trabalho, demiti-me da instituição particular para trabalhar como professor-concursado na Universidade Federal do Tocantins/Câmpus Universitário de Miracema. Para efetivação, o estágio probatório de 36 meses requer que o candidato apresente um plano de trabalho, com olhar no tripé que determina a razão de ser da instituição universitária: ensino, pesquisa e extensão.

Definiu-se desde o concurso a área do ensino que estaria sob a minha responsabilidade, isto é, a Prática de Ensino, objeto de preocupação dos estudos já citados. O segundo tópico, a extensão, é correlato ao ensino, em disponibilização no ano de 2006, com a colaboração de outro professor do curso intitulado: "O ensino de Filosofia e as epistemologias da prática". Por fim, a pesquisa, em continuidade ao objeto do meu interesse desde o final dos anos 1990, no caso, o ensino de Filosofia.

Enquanto na primeira pesquisa investiguei a prática dos professores de Filosofia nos anos iniciais do ensino superior, além de efetivação prática com o ensino através da pesquisa-ação e, na segunda pesquisa, nova prática por intermédio, novamente, da pesquisa-ação, na disciplina Prática de Ensino; ensaio, nesse instante, esquadrinhamento com os professores/trabalhadores, das condições do ensino de Filosofia em nível médio no Estado do Tocantins.

Inicialmente, um breve histórico da ausência/presença do ensino de Filosofia ao longo da educação escolar brasileira, para melhor contextualização do objeto de estudo. 


\section{A presença/ausência do ensino de Filosofia na educação escolar brasileira}

Para melhor encaminhamento do breve resgate da ausência/ presença do ensino de Filosofia na educação escolar brasileira, apropriarme-ei da seguinte configuração histórica brasileira: do Período Colonial até a República; da Primeira República ao Golpe Civil-Militar de 1964; Período Ditatorial, pós-1964; e Período da "Redemocratização" Política pós-1980.

Na primeira configuração, algumas subdivisões: Período Jesuítico, Período Pombalino e Período Imperial. No Período Jesuitico, uma concepção de ensino-aprendizagem de Filosofia marcadamente enciclopédica, de caráter autoritário e conservador, com base nas diretrizes da Companhia de Jesus ordem religiosa da Igreja católica -, responsável pela instrução e catequese na Colônia, em normas sistematizadas pelo Ratio Studiorum que "sintetiza a experiência pedagógica dos jesuítas, regulando cursos, programas, métodos e disciplina das escolas da Companhia" (PAIM, 1984, p. 210).

Realiza-se, aqui, um ensino de Filosofia de fundamentação epistemológica aristotélica-tomista, "com o maior 'cuidado', para que os alunos tomassem contato apenas com aquelas idéias do estagirita que não comprometessem o dogma católico" (ALVES, 2002, p. 10). Dentre outros aspectos, caracteriza-se, também, pela memorização e repetição dos conteúdos transmitidos, e por um rígido controle "sobre os professores e sobre as leituras feitas pelos alunos, para não os expor a nenhuma influência externa, a 'idéias novas' ou contrárias à doutrina da Igreja" (ALVES, 2002, p. 10-11). Diante dos tópicos salientados, uma pergunta: Para quem se direciona esse ensino? Para a formação de homens letrados, eruditos, principalmente, católicos, e, consequentemente, "prestando um serviço aos interesses da classe dirigente da colônia e da metrópole" (HORN, 2000, p. 20).

Contudo, em 1759, os padres jesuítas são expulsos da Colônia, na chamada Reforma Pombalina, empreendida num ideário filosófico de cunho iluminista pelo marquês de Pombal, "ameaçando" a concepção de ensino de cunho religioso que se propunha hegemônica. No Período Pombalino, em contraposição ao período anterior, o ensino de Filosofia estará acoplado, teoricamente, na perspectiva de corroboração dum saber da "ciência natural", num viés cartesiano-galileano de domínio do homem sobre o mundo natural a partir da observação e experimentação e, consequentemente, abominação às leituras de Aristóteles e de Tomás de Aquino. 
Em decorrência disso, a rígida visão administrativa jesuítica será reestruturada, num "novo ensino" ministrado por leigos, filhos de proprietários rurais (HORN, 2000, p. 21), que substituirá "um sistema orgânico, um currículo de cunho linear, ordenado, progressivo, com duração e conteúdos determinados, materiais e métodos específicos, por aulas avulsas de disciplinas isoladas" (EITERER, 2002, p. 473).

Entrementes, um caso singular: o Seminário de Olinda, na figura de Azeredo Coutinho, que aceitava as novas ideias liberais-iluministas, preocupava-se com a formação do filósofo naturalista, especificamente o cura (ALVES, 2002, p. 17) que, além de sua formação como religioso, tinha também como tarefa uma formação em "ciências naturais". Contudo, no geral, propicia-se, nesse período, um processo de ensino-aprendizagem ainda livresco, abstrato, preocupado com a elite intelectual, cujo trabalho estava sob o encargo dos escravos, em uma sociedade exclusivamente agrária. Ou melhor, os velhos ditames escolástico-jesuíticos enraizarão em nossa estrutura de ensino, que ainda se fará bem presente no Período Imperial.

No Período Imperial da história brasileira, uma preocupação inicial era a estruturação dum ensino superior para reprodução de quadros políticos e administrativos para a burocracia estatal, com vários cursos sendo criados medicina, cirurgia, matemática, agronomia, química, desenho, etc. -, em estabelecimentos isolados, ministrados com "livros-textos" das respectivas ciências citadas (ALVES, 2002, p. 20).

Por conseguinte, nesse momento da história do Brasil, o ensino de Filosofia assinalará um caráter propedêutico ao nível superior, simplesmente contribuindo para a formação do letrado, do bacharel e do doutor num intuito de erudição, dentro de um arcabouço transmissivo-assimilativo, fruto da concepção de ensino-aprendizagem da escolástica-jesuítica, com ênfase "dada a algumas áreas, principalmente lógica e ética, esta última quase sempre sob o título - e enfoque - 'moral"' (HORN, 2000, p. 24).

Entretanto, é do conhecimento dos estudiosos da história do ensino de Filosofia que do Período Colonial até o término do Período Imperial - presença garantida do ensino de Filosofia (ALVES, 2002) a ausência duma proposta metodológica alternativa para o ensino de Filosofia, com tal ensino baseando-se, preponderantemente, em manuais e compêndios, já prontos e direcionados, epistemologicamente, retirando, assim, a capacidade de criação de um ensino crítico, tanto por parte dos professores, quanto dos alunos. 
Passemos, agora, ao segundo momento histórico que vai da Primeira República ao Golpe Civil-Militar de 1964: presença indefinida do ensino de Filosofia (ALVES, 2002). Com a instituição da República no Brasil, em 1889, sob a influência da filosofia liberal-positivista, o ensino escolar passa a ser um veículo para disseminar os princípios e valores do novo modelo econômico e político, já que dentre "os princípios positivistas estava a crença na educação como chave para a resolução dos problemas do país" (SILVEIRA, 1991, p. 112). Este ponto de vista será norteado pelo movimento amplamente conhecido como entusiasmo pela educação e o otimismo pedagógico, que encadeará várias reformas no campo educacional.

A primeira reforma será inaugurada pelo positivista Benjamin Constant, primeiro ministro da Instrução Pública, no Decreto n. 981/1890, "antecipando-se à Constituição de 1891 nas reformas educacionais, buscando introduzir disciplinas científicas nos currículos escolares” (ALVES, 2002, p. 26-27). Porém, uma novidade: pela primeira vez o ensino de Filosofia fica ausente do ambiente organizacional de ensino na distribuição das disciplinas em séries, com repercussões até os dias atuais: "a Filosofia, tradicionalmente identificada com as humanidades literárias ou clássicas, torna-se alvo das críticas dos partidários do currículo centrado nas ciências" (ALVES, 2002, p. 28).

Assim, de agora em diante, mediante essa postura ideológica, o ensino de Filosofia ora estará presente - em momentos que o currículo priorizará o "espírito literário" - , ora estará ausente - em momentos que a prioridade ater-se ao "espírito científico". Exemplos para melhor corroboração da proposição (ALVES, 2002, p. 29): Reforma Epitácio Pessoa (1901): presença do ensino de Filosofia; Reforma Rivadávia Corrêa: retira-se o ensino de Filosofia do currículo; Reforma Carlos Maximiliano: retorno do ensino de Filosofia e, finalmente, Reforma Rocha Vaz (1925): ensino obrigatório de Filosofia. Para Alves (2002, p. 29), essa inconstância da presença/ausência desse ensino "prosseguiu indefinida por todo o Período Republicano, até as reformas curriculares dos dias atuais".

No período pós-1930, a Reforma Francisco Campos (1932), que criará o regime seriado de estudos, com dois ciclos - fundamental (formação básica geral) e complementar (preparação para o ingresso no ensino superior) -, manterá o ensino de Filosofia para esse último. Em seguida, a Reforma Gustavo Capanema (1942), estruturada em dois ciclos: ginásio (4 anos) e colégio (3 anos), com dois cursos: clássico, priorizando a formação intelectual; o científico, melhor aprofundamento das ciências. O ensino de Filosofia será indicado 
para ambos os cursos, evidentemente com maior ênfase no clássico. E como ele se processava? Em uma concepção enciclopédica e elitista, transmissiva e assimilativa, sem qualquer interesse por um ensino crítico-participativo. No começo da década de 1960, com a Lei n. 4.024/61 (BRASIL, 1942), o ensino de Filosofia não mais aparece como obrigatório, como na Reforma Gustavo Capanema, mas optativa.

Em decorrência de tantas alterações legais - anteriormente focalizado -, com o ensino de Filosofia a partir da Proclamação da República, mediante a variedade de políticas educacionais, observa-se, gradativamente, sua extinção, a qual se concretizará no período de 1964 a 1982, em uma "ausência definida" (ALVES, 2002). Assim, o ensino de Filosofia, não servindo aos interesses tecno-burocráticos e políticos-ideológicos dum modelo que se implementava, extinguiu-se, com a inclusão de outras disciplinas "que teriam o conteúdo correspondente ao da Filosofia. As disciplinas criadas foram: Educação Moral e Cívica (EMC), Organização Social e Política Brasileira (OSPB)" e estudos dos problemas brasileiros prevista para o nível superior (ALVES, 2002, p. 38-39). Não obstante, uma advertência: "Isto não significa que essas disciplinas comportassem os conteúdos da filosofia, ao contrário, mas era essa a idéia veiculada como uma das justificativas para não incluir a filosofia no currículo" (ALVES, 2002, p. 39). E para sinalizar o "golpe de misericórdia", a derrocada final dar-se-á com Lei de Diretrizes de Bases da Educação Nacional, Lei n. 5.692/71 (BRASIL, 1971), pela “expulsão" compulsória do ensino de Filosofia do nível secundário até os finais do regime ditatorial.

Porém, mesmo com a impossibilidade da presença do ensino de Filosofia, sempre existiu alguma pressão para o seu retorno, como disciplina obrigatória, mas as sequelas serão nefastas para os homens e mulheres que adentrarão o nível superior de ensino, principalmente naquelas instituições que, nos anos iniciais, implementarão o ensino de Filosofia. Isso se acentuará com a promulgação da nova Lei de Diretrizes e Bases da Educação Nacional, Lei n. 9.394/96 (BRASIL, 1996), por causa da ambigüidade no que se refere ao ensino de Filosofia no nível médio de ensino: "Os conteúdos, as metodologias e as formas de avaliação serão organizados de tal forma que ao final do ensino médio o educando demonstre: [...] o dominio dos conhecimentos de filosofia e de sociologia necessários ao exercício da cidadania [grifo meu]" (art. 36, \$1o, incisivo III). Qual é a ambiguidade? Não há nenhuma clareza se o ensino de Filosofia será concretamente trabalhado como disciplina ou será diluído nas outras áreas como tema transversal, projetos etc. Para Alves (2002, p. 54), essa ambiguidade 
“em seus termos pode e está gerando interpretações contraditórias, o que tende a inviabilizar, na prática, uma presença efetiva da filosofia no nível médio de ensino, ao contrário do que se imagina à primeira vista”.

Todavia, enquanto a legislação federal tornou-se um empecilho para a introdução do ensino de Filosofia no nível médio de ensino, por sua ambiguidade, educadores lutaram para a sua implementação como disciplina obrigatória, em viabilização, na prática, dum ensino crítico que possa contar com os interesses práticos dos seus alunos, principalmente aqueles que nem sequer tiveram contato com esse ensino anteriormente.

No tópico referente à defesa por um ensino crítico de Filosofia há o seguinte direcionamento, conforme pesquisada realizada (LIMA, 2005): há um posicionamento crítico dentro do espírito kantiano com ênfase num ensino que privilegie a história da filosofia:

embora Kant não estivesse muito preso à história da filosofia, as suas considerações a respeito da filosofia e do exercício da razão acabam confirmando a pertinência da história da filosofia no ensino da filosofia, tendo em vista "o exercício do pensamento, [...] a sua emancipação" (GUIDO, 2000, p. 84-90).

Tem-se, em vista disso, a seguinte objetivação: "fazer uso de seu entendimento sem a direção de outro indivíduo” (KANT, 1985, p. 100).

Outro caminho tem como referencial teórico-metodológico o pensamento gramsciano (ALVES, 2002; SILVEIRA, 1991, 2000, 2003). Pretende-se nessa proposta de ensino de Filosofia a superação do senso comum para poder forjar uma nova consciência, crítica e consciente, a partir da história da filosofia, já que "não se pode separar a filosofia da História da Filosofia” (GRAMSCI, 1989, p. 13). Eis a posição de um desses defensores: "Um ensino de Filosofia assim compreendido tem como objetivo primordial a instrumentalização teórico-prática dos estudantes, de modo a capacitá-los para uma compreensão mais fundamentada, mais elaborada e global da realidade em que vivem e, conseqüentemente, para uma intervenção mais consciente e crítica” (SILVEIRA, 2000, p. 138).

Outra proposta bastante polêmica refere-se à definição da Filosofia como "disciplina que consiste em criar conceitos" (DELEUZE; GUATTARI, 1992, p. 13) e sua transposição para o ensino de Filosofia. Para o defensor desse encaminhamento, "não se ensina filosofia impunemente; não se aprende filosofia impunemente. A 'oficina de conceitos' é um local perigoso, de 
onde podem trocar conceitos que sejam ferramentas para mudar o mundo" (GALLO, 2002, p. 208). Tal vertente possibilita, portanto, criticamente, um ensino de Filosofia como possibilidade de criação (de conceitos), sendo tal criação uma intervenção no mundo. Ou melhor, a criação de conceitos é a própria criação de um mundo.

Com base nas lutas dos trabalhadores do ensino em Filosofia, por exemplo, os Simpósios Sul-Brasileiros sobre o Ensino de Filosofia, em 7 de julho de 2006, o Parecer CNE/CEB n. 38/2006 (BRASIL, 2006) decide pela inclusão obrigatória das disciplinas de Filosofia e Sociologia no currículo do ensino médio, em sua homologação pelo Ministro da Educação, Fernando Haddad, no dia 11 de agosto de 2006. Em 2 de junho de 2008, o Presidente da República em exercício, José Alencar, sancionou a Lei n. 11684/08 (BRASIL, 1946), que torna obrigatório o ensino de Filosofia e Sociologia nos três anos do Ensino Médio, em alteração, assim, do Art. 36 da LDB. A lei foi aprovada primeiro na Câmara dos Deputados, na qual o projeto começou a tramitar em 2003, e no dia 8 de maio de 2008, no Senado.

Por ora, uma curiosidade que me leva à investigação a respeito da situação do ensino de Filosofia no Estado do Tocantins. Em pesquisa desenvolvida por solicitação da Unesco, cinco pesquisadores mapeiam as condições de ensino de Filosofia nas diversas regiões brasileiras, em seus diversos níveis, com especial ênfase na educação média. Todavia, avisam: "não se constitui [...] num esforço analítico, mas oferece uma descrição, a mais detalhada possível, das distintas condições do ensino de Filosofia nas diversas regiões brasileiras naquele momento" (FÁVERO et al., 2004, p. 257).

Entrementes, o Estado do Tocantins somente aparece no que diz respeito à quantificação de aulas semanais de Filosofia no Ensino Médio:

Estados que adotam a disciplina, em toda a rede pública, com ao menos duas semanais durante um ano/série [grifo dos autores]: 13 (Acre, Alagoas, Amazonas, Bahia, Goiás, Maranhão, Pará, Piauí, Rio de Janeiro, Roraima, Santa Catarina, Sergipe e Tocantins [grifo meu] (FÁVERO; CEPPAS; GONTIJO; GALLO \& KOHAN, 2004, p. 263).

Diante disso, a seguinte inquirição: Quais são as condições do ensino de Filosofia, em nivel médio, na rede pública de ensino do Estado do Tocantins? Saliento, desde já, que essa pesquisa tem o seguinte objetivo geral: Investigar, entre os(as) professores(as) / trabalhadores(as), as condições do ensino de Filosofia no Estado do Tocantins na rede pública de ensino, com ênfase no ensino 
médio; consequentemente, dois objetivos específicos: (i) buscar subsídios para intervenção prática conforme o fiz no mestrado e no doutorado, num contexto de retorno obrigatório da Filosofia para o nível médio de ensino e, por fim, (ii) servir de auxílio à criação do curso de Filosofia na Universidade Federal do Tocantins.

\section{Metodologia}

Para concretização do objetivo geral dessa pesquisa - Investigar, entre os(as) professores(as)/trabalhadores(as), as condições do ensino de Filosofia no Estado do Tocantins na rede pública de ensino, com ênfase no Ensino Médio - foi realizado exame bibliográfico para buscar teses e dissertações voltados ao estudo sobre as condições do ensino de Filosofia em algum Estado ou Cidade da Federação Brasileira, em vista, também, de instrumento de pesquisa para melhor delineamento do meu trabalho. Na garimpagem encontrei três trabalhos: Horn (2002), Nascimento (2002) e Carminati (2003).

Horn (2002) examina minuciosamente, em seu trabalho de doutorado, as questões que emergem das práticas pedagógicas do ensino de Filosofia no Estado do Paraná, bem como as possibilidades de ampliação do espaço e da pertinência na disciplina da escola. Inicialmente faz inventário das universidades do Estado do Paraná para o conhecimento de suas propostas de formação de professores de Filosofia. E, por fim, a pesquisa dirigiu-se aos professores da rede pública de ensino no Estado do Paraná para coleta de dados que permitiram traçar o perfil do professor de Filosofia quanto à sua formação, regime de trabalho, formação acadêmica, ano de conclusão da graduação, disciplinas que lecionam, tempo de docência, perspectivas docentes quanto ao ensino de Filosofia, os objetivos que perseguem quanto ao ensino, como realizam a seleção, organização e desenvolvimento dos conteúdos filosóficos em sala de aula.

Nascimento (2002) trata do ensino de Filosofia na educação de nível médio em Teresina (PI) e a relação da formação inicial do professor de Filosofia adquirida no curso de Filosofia da Universidade Federal do Piauí e a sua prática pedagógica. Nesse trabalho de mestrado, a pesquisadora aprofundou a mediação entre formação e prática docente, em observação, segundo as vozes dos sujeitos envolvidos com o ensino de Filosofia, as competências que devem possuir os professores de Filosofia para assunção da tarefa de realizar com os jovens, na educação escolar, a reflexão e o debate filosófico. Tentou-se compreender qual 
o saber ou o conhecimento necessário à constituição de um perfil docente para o exercício dessa disciplina e o tipo de formação inicial adequado à preparação do professor de Filosofia para o Ensino Médio, indagando o papel do curso de Filosofia da Universidade Federal do Piauí na formação desse licenciado.

Carminati (2003), em seu trabalho de doutorado, discutiu a formação e a prática pedagógica dos professores que lecionam a disciplina de Filosofia nas escolas de ensino médio pertencentes à Primeira Regional de Ensino (CRE), situadas no município de Florianópolis. Ou melhor: procurou compreender as relações entre os conhecimentos especializados da formação inicial e os saberes da prática. Os três pesquisadores fizeram uso do instrumento de pesquisa denominado de questionário. Aproprieime do questionário elaborado por esse pesquisador para compreensão das condições do ensino de Filosofia no Estado do Tocantins.

Com o questionário em mãos, solicitei à Secretaria de Educação do Estado do Tocantins (SEDUC), o envio do instrumento de pesquisa para os professores de Filosofia. Com a liberação por parte da Secretaria de Educação, a própria secretária ficou responsável pelo envio de 553 questionários aos professores que ministravam a disciplina de Filosofia às respectivas Diretorias de Ensino - Araguaína, Araguatins, Arraias, Colinas, Dianópolis, Guaraí, Gurupi, Miracema, Palmas, Paraíso, Pedro Afonso, Porto, Tocantinópolis. Em resposta, retorno de 184 questionários, ou melhor, 33,27\%.

A seguir, resumidamente, as conclusões sobre as condições do ensino de Filosofia no Estado do Tocantins.

\section{Considerações sobre as condições do ensino de Filosofia no Estado do Tocantins}

Em decorrência de estudo realizado por cinco pesquisadores (FÁVERO et al., 2004) que estudaram as condições do ensino de Filosofia no Brasil por solicitação da Unesco, pus-me a seguinte inquirição: Quais são as condições do ensino de Filosofia, em nível médio, na rede pública de ensino do Estado do Tocantins? Possibilitava, assim, melhor conhecimento sobre a situação do ensino de Filosofia nesse Estado da região Norte do Brasil, já que não era essa a intenção dos estudiosos acima citados. Entretanto, já traziam uma informação: a quantificação de aulas semanais de Filosofia no ensino médio, no caso, ao menos duas aulas semanais durante um ano/série. 
O primeiro aspecto desse estudo sobre as condições do ensino de Filosofia no Estado do Tocantins que me chamou a atenção, refere-se à titulação dos entrevistados: apenas $14 \%$ são formados em Filosofia, enquanto que 52\% são formados em Pedagogia e História; porém, um dado preocupante é que a disciplina Filosofia é vista, simplesmente, como complementação de carga horária, pois somente 4,4\% dos professores lecionam somente essa área do conhecimento no ensino médio.

Salienta-se, assim, a importância de um curso de Filosofia em nível público e gratuito, no caso, a Universidade Federal do Tocantins, para a formação de professores para o trabalho com o ensino de Filosofia no ensino médio, além de luta árdua para sua implantação - no mínimo com carga horária específica de $2 / 3$ aulas por semana, em todos os anos do nível médio -, mesmo com a sua obrigatoriedade conforme Parecer n. 38/2006 do Conselho Nacional de Educação. Todavia, mesmo mediante a nãoformação específica, 63\% dos professores que trabalham com o ensino de Filosofia no Estado do Tocantins estão satisfeitos e afirmam ter afinidade com a disciplina, pois esta amplia os conhecimentos e promove a reflexão.

Outro tópico dessa pesquisa é que, dos professores formados em Filosofia, 27\% prestaram vestibular nessa área do conhecimento porque sempre gostaram das temáticas específicas da Filosofia; para 15\% deles, a escolha foi por acaso, isto é, sem intenção definida; 15\% fizeram vestibular para Filosofia tendo em vista a pesquisa; $15 \%$ indicaram outras razões, como: eram seminaristas e o estudo da Teologia exige primeiramente o estudo da Filosofia; promoção humana, autoconhecimento; curso que não tinha a disciplina Matemática e, por fim, curiosidade de descobrir sobre o mundo. Dois aspectos chamaram-me a atenção: apenas 12\% estudaram Filosofia para o exercício do magistério no ensino médio e $43 \%$ dos professores que prestaram vestibular para Filosofia escolheriam outro curso, como: Antropologia, Direito, Engenharia Ambiental, Geografia, História, Letras, Psicologia, Sociologia.

Dos professores que trabalham com o ensino de Filosofia, formados ou não na área, 41\% responderam que às vezes leem revistas/periódicos de Filosofia e 35\% responderam que leem sempre, sendo os mais citados: Mundo Jovem; livros didáticos; revistas: Veja, Nova Escola; Istoé; Discutindo Filosofia e a Revista Brasileira de Filosofia. Saliento a informação de que algumas escolas não recebem revistas e periódicos de Filosofia, dificultando, assim, que o professor se prepare adequadamente para o trabalho com a Filosofia. 
Porém, conforme dados da pesquisa, são utilizados em sala de aula os seguintes livros didáticos: Filosofando, Convite à Filosofia, Introdução à Filosofia, Temas de Filosofia, os quais, provavelmente, servem de material de estudo para os professores. Diante disso, urge a produção de algum material didático para o ensino de Filosofia, no caso, por exemplo, compilação de textos para serem trabalhados no dia a dia das escolas públicas de ensino médio no Estado do Tocantins; além de investimento na formação profissional, por parte dos setores públicos - intenção de $80 \%$ dos professores, na pretensão de dominar os temas propostos em Filosofia - em indicação, por eles: Ética e Política.

Alguns professores também afirmaram não haver formação continuada em Filosofia por parte da Secretaria de Educação do Estado do Tocantins.

Em decorrência, 90\% dos professores que lecionam a disciplina de Filosofia no Estado do Tocantins afirmam ser importante a formação didático-metodológica para melhor desempenho da prática pedagógica, com obrigatoriedade por parte de $57 \%$ dos pesquisados. Todavia, uma informação chama a atenção: somente $32 \%$ dos professores disseram que a formação deveria ser por meio de cursos extracurriculares na própria instituição, em fóruns e cursos que discutissem os temas de Filosofia.

Quando os professores foram inquiridos a respeito do início do trabalho docente em Filosofia, 74\% responderam que sempre/quase sempre a leitura dos livros didáticos de Filosofia foi recurso importante para o início da prática pedagógica, além de forte auxílio na aquisição das habilidades didático-metodológicas. Penso que essa resposta élugar-comum daqueles que se propõem ao trabalho com o ensino de Filosofia, em busca de como lidar no dia a dia com uma disciplina que simplesmente serve para complementação de carga horária. Todavia, mesmo diante dessas informações, $70 \%$ dos pesquisados informaram que as habilidades didáticometodológicas são adquiridas na prática cotidiana da sala de aula.

Quanto às finalidades do ensino de Filosofia no ensino médio, dois lugares foram importantes, na seguinte ordem: o ensino da Filosofia enquanto problematizadora do conhecimento e o ensino da Filosofia enquanto exercício da crítica. Penso que se complementam, para melhor responder ao objetivo do ensino de Filosofia para os entrevistados: evidenciar a complexidade dos problemas do mundo contemporâneo, com ênfase nas temáticas atuais, e, por fim, para que isso ocorra, a importância de textos filosóficos para leitura e discussão em grupo, conforme corroboração dos pesquisados. 


\section{Referências}

ALVES, D. J. A filosofia no ensino médio: ambigüidade e contradições na LDB. Campinas, SP: Autores Associados, 2002.

BRASIL. Decreto-lei n. 4.244, de 09 de abril de 1942. Lei orgânica do ensino secundário. Coleção de Leis do Brasil, Poder Executivo, Brasília, DF, 31 dez. 1942. v. 3, p. 20 Disponível em:< http://www6.senado.gov.br/legislacao/ ListaTextoIntegral.action?id=3081>. Acesso em: 7 jun. 2009.

. Lei n ${ }^{\circ}$ 11684/08, 12 ago. 1946. Modifica disposições do Decreto-lei n ${ }^{\circ} 4.481$, de 16 de Julho de 1942. Diário Oficial [da] República Federativa do Brasil, Poder Legislativo, Brasilia, DF, 12 ago. 1946. Disponível em: < http:/ /www6.senado.gov.br/ sicon/ExecutaPesquisaBasica.action>. Acesso em: 23 fev. 2009.

. Lei n. 5.692, de 11 de agosto de 1971. Fixa diretrizes e bases para o ensino de primeiro e segundo graus, e da outras providencias. Diário Oficial [da] República Federativa do Brasil, Poder Legislativo, Brasilia, DF, 12 ago. 1971. p. 6377. Disponível em: <http://www6.senado.gov.br/legislacao/ListaTextoIntegral.action?id=75576>. Acesso em: 23 fev. 2009.

. Lei n. 9.394, de 20 de dezembro de 1996. Estabelece as diretrizes e bases da educação nacional. Diário Oficial [da] República Federativa do Brasil, Poder Legislativo, Brasilia, DF, 23 dez. 1996. p. 27833. Disponível em: <http:// www6.senado.gov.br/legislacao/ListaTextoIntegral.action?id $=75723>$. Acesso em: 23 fev. 2009.

. Parecer CNE/CEB n. 38/2006, de 7 de julho de 2006. Inclusão obrigatória das disciplinas de Filosofia e Sociologia no currículo do Ensino Médio. Diário Oficial [da] República Federativa do Brasil, Ministério da Educação, Brasília, DF, 14 ago. 2006. Disponível em: <http://www.filoeduc.org/gt/pceb038_06. pdf>. Acesso em: 7 jan. 2009.

CARMINATI, C. J. Formação e docência: a trajetória de professores de Filosofia no ensino médio. 2003. 136 f. Tese (Doutorado em Educação) - Faculdade de Educação/UFSC, 2003.

DELEUZE, G.; GUATTTARI, F. O que é filosofia? Tradução de Bento Prado Júnior e Alberto Alonso Muñoz. Rio de Janeiro: Editora 34, 1992. 
EITERER, C. L. Da Companhia de Jesus aos nossos dias: um comentário sobre a história do ensino de Filosofia na escola média no Brasil. In: PIOVESAN, A. et al. (Org.). Filosofia e ensino em debate. Ijuí: Ed. da UNIJUÍ, 2002. p. 471-481. FÁVERO, A. A. et al. O ensino da filosofia no Brasil: um mapa das condições atuais. Caderno Cedes, v. 24, n. 64, p. 257-280, 2004.

GALLO, S. A especificidade do ensino de Filosofia: em torno dos conceitos. In: PIOVESAN, A. et al. Filosofia e ensino em debate. Ijuí: Ed. UNIJUÍ, 2002. p. 193-209.

GRAMSCI, A. Concepção dialética de história. Tradução de Carlos Nelson Coutinho. 8. ed. Rio de Janeiro: Civilização Brasileira, 1989.

GUIDO, H. A. O. A filosofia no ensino médio: uma disciplina necessária. In: GALLO, S.; KOHAN, W. O. (Org.). Filosofia no ensino médio. Petrópolis: Vozes, 2000. p. 84-90.

HORN, G. B. A presença da Filosofia no currículo do ensino médio brasileiro: uma perspectiva histórica. In: GALLO, S.; KOHAN, W. O. (Org.). Filosofia no ensino médio. Petrópolis: Vozes, 2000. p. 17-33.

HORN, G. B. Por uma mediação praxiológica do saber filosófico no ensino médio: análise e proposição a partir da experiência. 2002. 275 f. Tese (Doutorado em Educação) - Faculdade de Educação Universidade São Paulo, São Paulo, 2002.

KANT, I. Textos Seletos. 2. ed. Tradução de Floriano de Souza Fernandes. Petrópolis: Vozes, 1985.

LIMA, M. A. C. O ensino de filosofia e suas contradições. Governador Valadares: Ed. da Univale, 2002.

LIMA, M. A. C. A Prática de Ensino de Filosofia num contexto de reestruturação: construção de uma experiência problematizadora com o ensino. 2005. 240 f. Tese (Doutorado em Educação) - Faculdade de Educação/UFMG, Belo Horizonte, 2005.

NASCIMENTO, E. M. M. do. O ensino de filosofia na educação de nível médio em Teresina (PI): relação entre formação inicial e prática pedagógica do(a) professor(a) de Filosofia. 2002. 136 f. Dissertação (Mestrado em Educação) - Faculdade de Educação/UFPI, Teresina, 2002. 
PAIM, A. História das idéias filosóficas no Brasil. 3. ed. São Paulo: Convívio, 1984.

SILVEIRA, R. J.T. Ensino de filosofia: em busca de um sentido. 1991. 176 f. Dissertação (Mestrado em Educação) - Universidade Estadual de Campinas, Campinas, 1991.

SILVEIRA, R. J.T. Um sentido para o ensino de filosofia no nível médio. In: GALLO, S.; KOHAN, W. O. (Org.). Filosofia no ensino médio. Petrópolis: Vozes, 2000. p. 129-148.

SILVEIRA, R. J. T. Matthew Lipman e a filosofia para crianças: três polêmicas. Campinas, SP: Autores Associados, 2003.

Recebido: 04/05/2009

Received: 05/04/2009

Aprovado: 26/06/2009 Approved: 06/26/2009 